\title{
Experimental study on mechanical properties of three steels
}

\author{
J.G. Qin*, Y.L. Lin, F.Y. Lu, and X.J. Wen \\ College of Science, National University of Defense Technology, 410073 Changsha, Hunan, P.R. China
}

\begin{abstract}
Tensile properties of three steels named A, B, and C were investigated. The quasi-static experiments were carried out by using WDW-100D computer control testing machine while the high strain-rate experiments were testing by using the Split Hopkinson Tensile Bars (SHTB). The stress-strain curves of the materials were obtained, tensile strength, elongation, and energy dissipated were acquired. From the experimental results, the Jonson-Cook constitutive model was use to describe the behaviours of materials. The results showed that steel B had highest tensile strength and lowest elongation than steel A and B. The Jonson-Cook constitutive model fit followed the experimental data very well.
\end{abstract}

\section{Introduction}

In order to improve manufacturability and reduce weight, the demand for high-strength ship parts and the development of high-strength steels with excellent ductility have increased. On the other hand, the shipbuilding materials are usually under high strain rate loadings when the ship is suffered attacked. So it is important to investigate the mechanical behaviour of shipbuilding steels under dynamic loading, and compare the result with the quasi-static tests.

There is a lot of literature about high strain rate behaviours of steels [1-5]. Given that the strain rate is well known to influence the mechanical behaviour, the determination of the material properties over a large range of strain rates is a key step towards the accurate modelling of ship crash tests and of several high-speed forming processes. The main experimental technique for the dynamic characterization of thin steel sheets in the range of strain rates from $10^{2}$ to $10^{3} \mathrm{~s}^{-1}$ is the Split Hopkinson bar [6]. It should be stated that these high strain rate experiments are accompanied with a noticeable temperature rise in the specimen, which causes thermal softening of the overall mechanical response of the specimen. This adiabatic process has to compete with the strain and strainrate hardening of the material during deformation.

In order to assess the contribution of the strain, strain rate and temperature rise further, the overall material response can be represented by several constitutive models. In this paper, the dynamic behaviour of three different shipbuilding steels is investigated. The Johnson-Cook model is validated on these materials to describe their high strain rate and temperature-dependent behaviour.

\section{Experimental procedures}

Three commercially available sheet steels A, B, C are examined in this study. Table 1 lists the chemical composition of these materials. The samples in this study are

*Corresponding author. Tel.:+86-0731-84573276; fax:+860731-84573297.

E-mail address: jg_qin@yahoo.cn
Table 1. Chemical composition of the investigated steel grade (in weight percent).

\begin{tabular}{|c|c|c|c|c|c|c|c|}
\hline Steel grade & $\mathrm{C}$ & $\mathrm{Si}$ & $\mathrm{Mn}$ & \multicolumn{1}{c|}{$\mathrm{P}$} & \multicolumn{1}{|c|}{$\mathrm{S}$} & $\mathrm{Ni}$ & $\mathrm{Cr}$ \\
\hline A & 0.11 & 0.72 & 1.31 & 0.009 & 0.006 & 0.63 & 0.65 \\
\hline $\mathrm{B}$ & 0.11 & 0.18 & 0.44 & 0.023 & 0.03 & 2.68 & 0.97 \\
\hline C & 0.12 & 0.6 & 1.2 & 0.025 & 0.015 & 1.1 & 0.5 \\
\hline
\end{tabular}

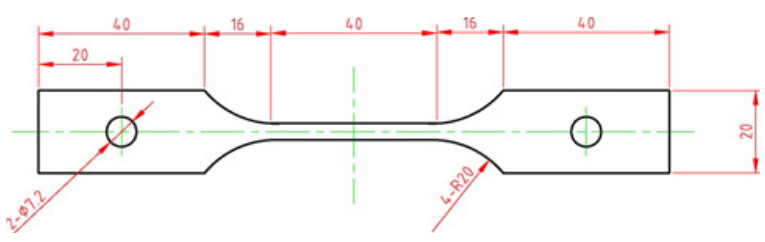

Fig. 1. Specimen geometry for quasi-static tests.

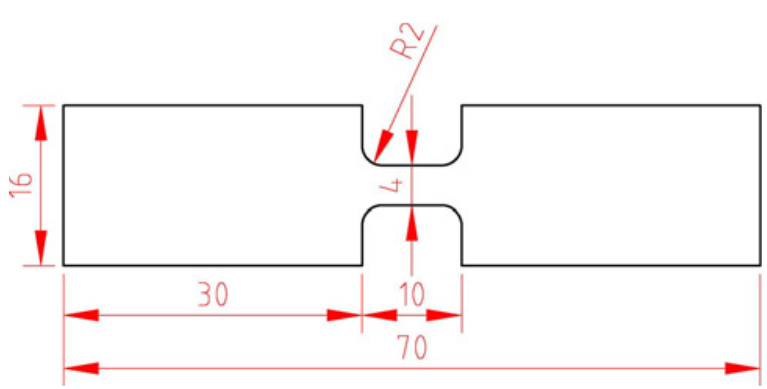

Fig. 2. Specimen geometry for tensile impact tests.

all prepared with electron discharge machining along the sheet rolling direction. The specimens, with dumbbellshaped flat, $1.8 \mathrm{~mm}$ thickness, are illustrated in Figs. 1 and 2 for quasi-static and tensile impact, respectively. A refractory inorganic adhesive was used to connect dynamic specimen with incident/transmitted bars, as shown in Fig. 3. The thickness of each adhesive layer was $0.10 \mathrm{~mm}$.

The quasi-static tests were performed on WDW-100D computer control testing machine with the strain rate of $1.1 \times 10^{-3} \mathrm{~s}^{-1}$.

A split Hopkinson tensile bar (SHTB) apparatus is used to characterize the dynamic properties of the investigated materials (Fig. 4). It mainly consists of two aluminium bars with a diameter of $20 \mathrm{~mm}$, i.e. the input and the output 


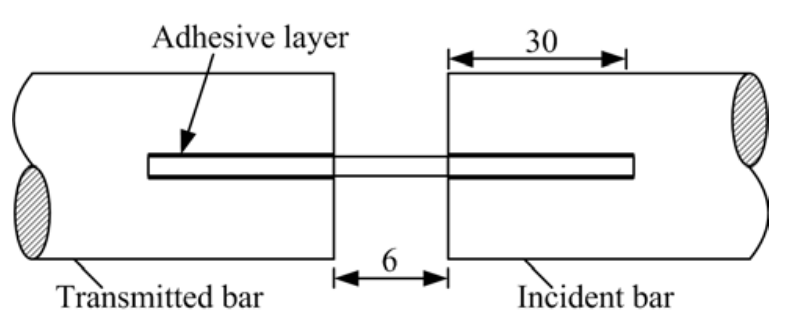

Fig. 3. Connection of specimen to bars.

bar (measuring $3.3 \mathrm{~m}$ and $1.8 \mathrm{~m}$ in length, respectively) between which a specimen of the test material is attached. A striker made of a hollow tube that is accelerated towards the anvil of the input bar produces an incident tensile wave in the input bar which travels towards the specimen, where it interacts with this specimen and is partly reflected back into the input bar. The other part, the transmitted wave, travels along the output bar. The strain histories of the different waves (incident, reflected and transmitted wave, respectively denoted as $\varepsilon_{i}(t), \varepsilon_{r}(t), \varepsilon_{t}(t)$, are recorded by means of strain gauges mounted on both bars. By adjusting the impact speed of the striker the strain rate can be varied.

According to the one-dimensional wave theory and the assumption of a uniaxial and homogeneous stress and strain in the specimen, the stress, strain and strain rate in the specimen can be written as follows [7]:

$$
\begin{gathered}
\sigma(t)=\frac{E_{b} A_{b}}{A_{s}} \varepsilon_{t}(t) \\
\varepsilon(t)=\frac{U_{o b}-U_{i b}}{L_{s}}=-\frac{2 C_{b}}{L_{s}} \int_{0}^{t} \varepsilon_{r}(\tau) d \tau \\
\dot{\varepsilon}(t)=\frac{V_{o b}-V_{i b}}{L_{s}}=-\frac{2 C_{b}}{L_{s}} \varepsilon_{r}(t)
\end{gathered}
$$

Where $A_{s}$ and $L_{s}$ are the cross-sectional area and the length of the testing region of the specimen. $C_{b}$ is the one-dimensional elastic stress wave velocity in the input/output bar material, $A_{b}$ the cross-section area and $E_{b}$ Young's modulus of the input/output bar, $U_{i b}$ and $U_{o b}$ the displacements of the specimen/input bar interface and the specimen/output bar interface and $V_{i b}$ and $V_{o b}$ are the corresponding interface velocities.

\section{Results and discussion}

\subsection{Stress-strain relation}

In the SHTB test, all the three steels A, B, C are investigated under three representative dynamic strain rate loadings: high $\left(\sim 3200 \mathrm{~s}^{-1}\right.$, short for $\left.\mathrm{H}\right)$, middle $\left(\sim 1800 \mathrm{~s}^{-1}\right.$, short for $\mathrm{M})$, and low $\left(\sim 1100 \mathrm{~s}^{-1}\right.$, short for L). Five specimens are tested at each set of conditions. Figure 5 is the comparison of curves about true stress vs. true strain of steel A under high strain rate loading. It is seen in Figure
5, five curves overlap each others except there is a little scatter at the end of the curves. So the results of tests are very repeatable.

In Fig. 6 8, a quasi-static and three dynamic stressstrain curves are given for all investigated materials (Table 1). Significant differences can be noticed between the quasi-static and dynamic curves. It is clear that all the three steels exhibit a positive strain rate dependence: stress levels rise as the strain rate increases from quasi-static to dynamic strain rates. However, in the range of dynamic strain rates considered here, only minor differences exist between the dynamic curves. This behavior is expected since it has been shown that the flow stress has a logarithmic dependence on strain rate for this type of materials. It is seen in Fig. 6 8 the slopes of stress between yield stress and tensile strength are nearly parallel, so there is little change in the hardening rate as strain rate is increased.

In Fig. 9, the tensile strength and yield stress as a function of dynamic strain rate is given. Under the dynamic loading, the tensile strength and yield stress of all three steel show mild differences as strain rate increased. Steel $B$ shows the highest tensile strength and yield stress, the value of steel $\mathrm{A}$ and steel $\mathrm{C}$ show almost the same. In Fig. 10, the tensile strength and yield stress under dynamic loading of three steels are much higher than that under quasi-static loading. The tensile strength is more stronger dependence on logarithm of strain rate than yield stress.

In Fig. 11, the fracture elongation and uniform elongation under dynamic loading are represented. The fracture elongation and uniform elongation of all three steel show mild differences as strain rate increased in the range of dynamic strain rates. Steel B shows the lowest fracture elongation and uniform elongation, the value of steel A and steel $\mathrm{C}$ show almost the same. In Fig. 12, the fracture elongations under dynamic loading of three steels are much higher than that under quasi-static loading, present stronge dependent on strain rate. But the uniform elongations represent little varieties from quasi-static loading, present very little dependent on strain rate.

Usually high strength steel performs low ductile. Different parameters can be used to evaluate the crash resistance performance of steels. The energy absorbed equaled the area value under true stress vs. true strain curve by the material gives valuable information. In Fig. 13, the comparison of energy dissipated by the three steels under different strain rate is given. From the figure, it is clear that, under quasi-static loading, energy dissipated of steel A is the highest, the values of steel B and steel C are almost equal. Under dynamic loading, energies dissipated of three steels show little different. And compare dynamic loading to quasi-static loading, there are significant increases of energies absorbed as strain rate increased.

\subsection{Constituent behaviour}

Several constitutive equations that describe the viscoelasto-plastic behavior of steels are available $[8,9]$. The proposed models are phenomenological, based on readily available, macroscopic parameters of the typical conditions during high-strain-rate loading; i.e., strain hardening, 


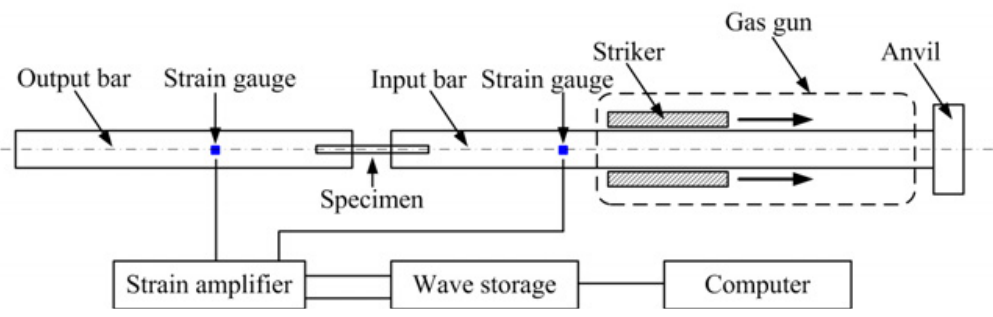

Fig. 4. Schematic representation of a SHTB setup.

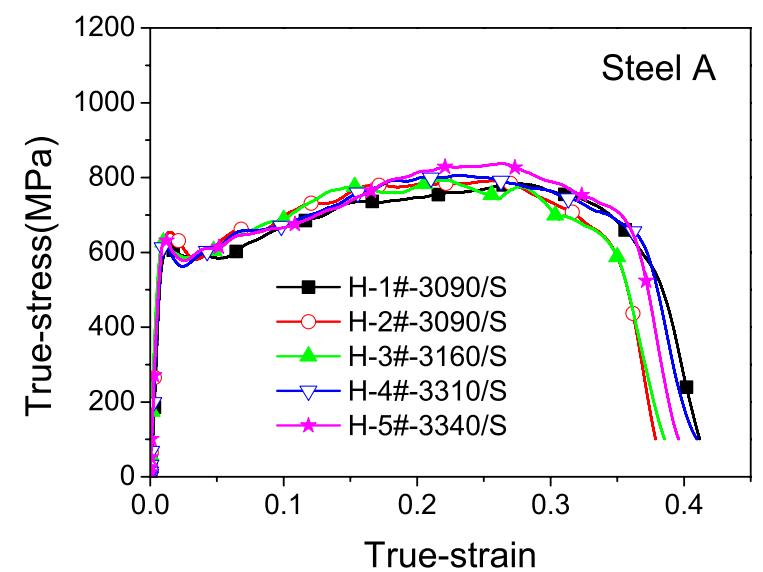

Fig. 5. Stress-strain curves of steel A under high strain rate loadings.

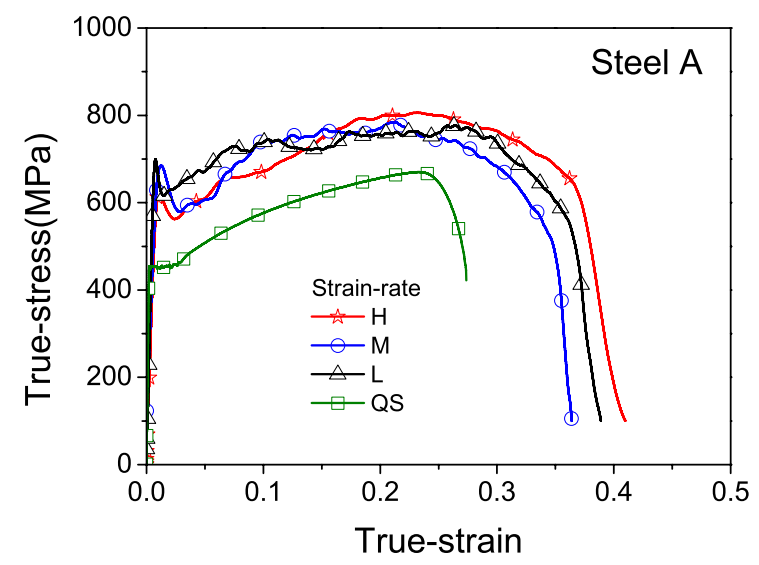

Fig. 6. Representative stress-strain curves of steel A.

strain rate hardening, and thermal softening are accounted for.

The quasi-adiabatic temperature increase in the specimen during plastic deformation is calculated using the following equation [10]:

$$
\Delta T=\beta \frac{1}{\rho c} \int \sigma d \varepsilon_{p}
$$

In this equation, $\rho$ is the mass density, $c$ the specific heat, and $\beta$ a coefficient indicating the fraction of plastic work converted to heat. The value of $\beta$ is usually assumed to be between 0.9 and 1 . Next to the heat due to plastic deformation given by Eq. (4). Since the exact evolution of the transformation during a high-strain-rate

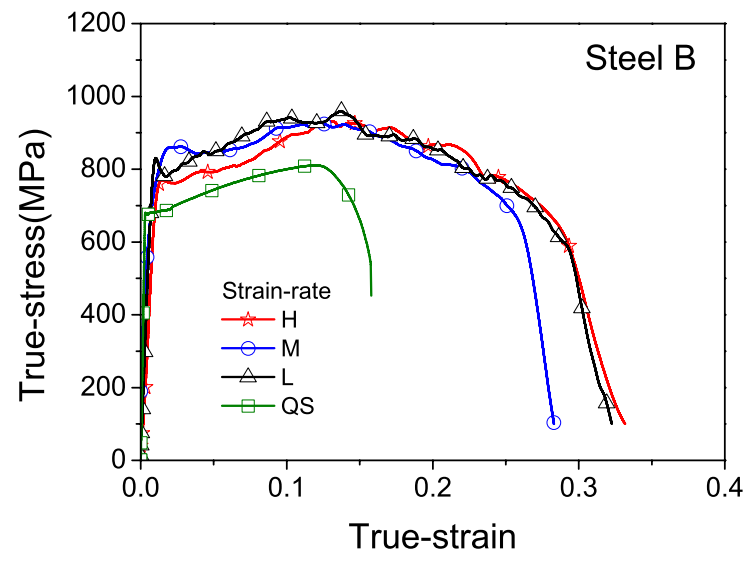

Fig. 7. Representative stress-strain curves of steel B.

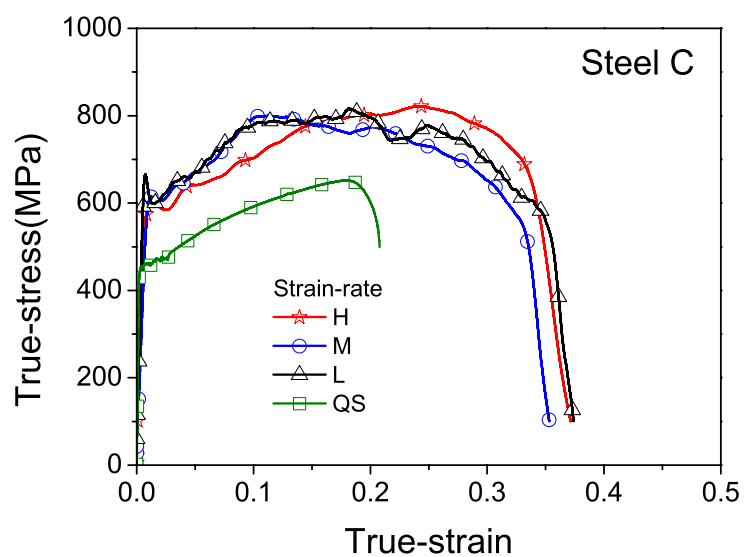

Fig. 8. Representative stress-strain curves of steel C.

experiment is not known yet, a value of 1 is used for the $\beta$-coefficient to allow additional heat release. During the test, the temperature will gradually change from room temperature to approximately $90{ }^{\circ} \mathrm{C}$. For each value of strain, the according temperature was thus calculated and integrated in the model, so that the gradual temperature rise is put into account.

The experimental data on the three steels are used to validate the Johnson-Cook model [8]. The Johnson-Cook model gives a linear increase of the true stress $s$ with the logarithm of the strain rates. The equation is a product of three factors: strain hardening, strain-rate hardening, and a thermal softening term:

$$
\sigma=\left(A+B \varepsilon_{P}^{n}\right)\left(1+C \ln \frac{\dot{\varepsilon}}{\dot{\varepsilon}_{0}}\right)\left[1-\left(\frac{T-T_{\text {room }}}{T_{\text {melt }}-T_{\text {room }}}\right)^{m}\right]
$$




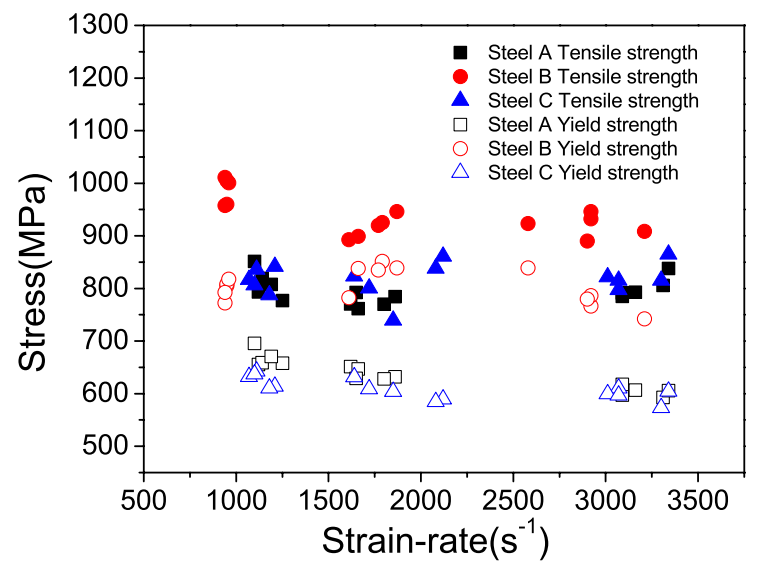

Fig. 9. Influence of the strain rate in the dynamic region on the tensile strength and yield strength.

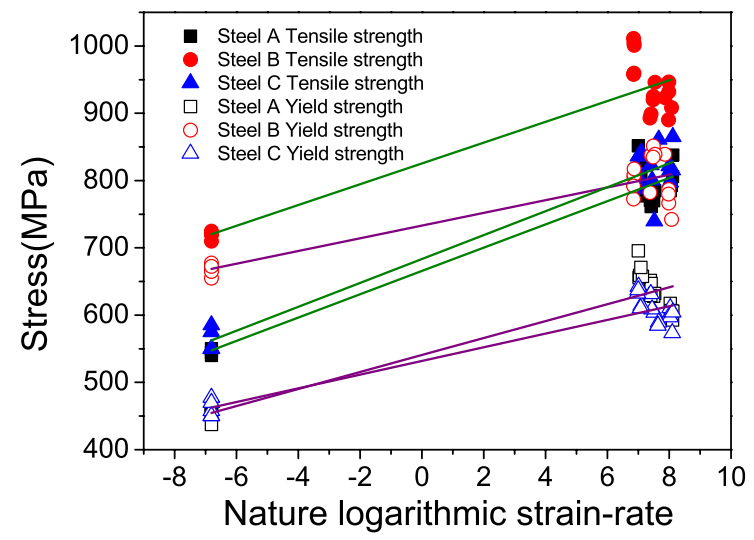

Fig. 10. Influence of the strain rate from the quasi-static to the dynamic region on the tensile strength and yield strength.

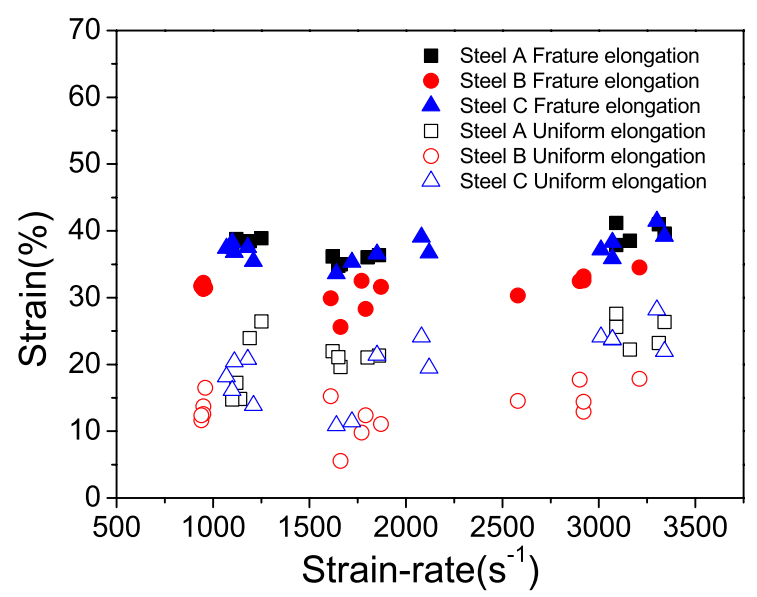

Fig. 11. Influence of the strain rate in the dynamic region on the fracture elongation and uniform elongation.

where $\varepsilon_{p}$ is the true strain, $\dot{\varepsilon}$ is the strain rate, $\dot{\varepsilon}_{0}$ a reference value of the strain rate $\left(1.1 \times 10^{-3} \mathrm{~s}^{-1}\right), T$ the temperature. The procedure to determine parameters is described hereunder.

Step 1: Change all the true stress vs. true strain curves into true stress vs. effective plastic strain curves. The parameters $A, B$, and $n$ can be obtained from the quasi-

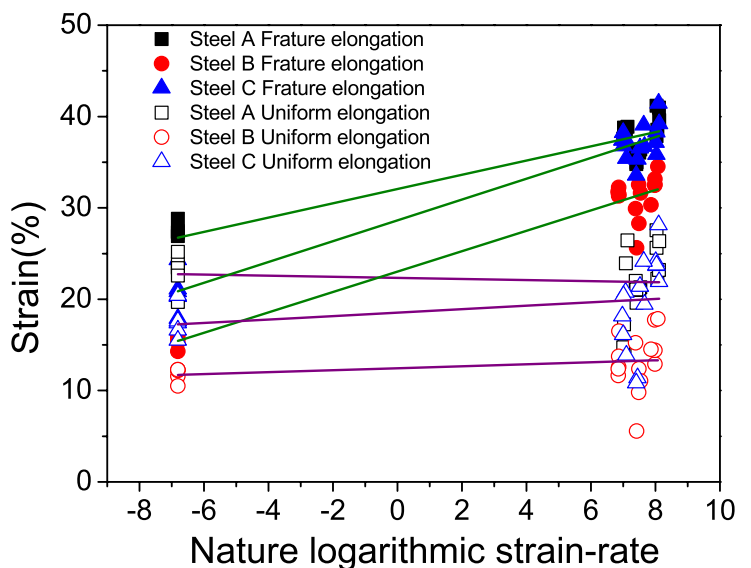

Fig. 12. Influence of the strain rate from the quasi-static to the dynamic region on the fracture elongation and uniform elongation.

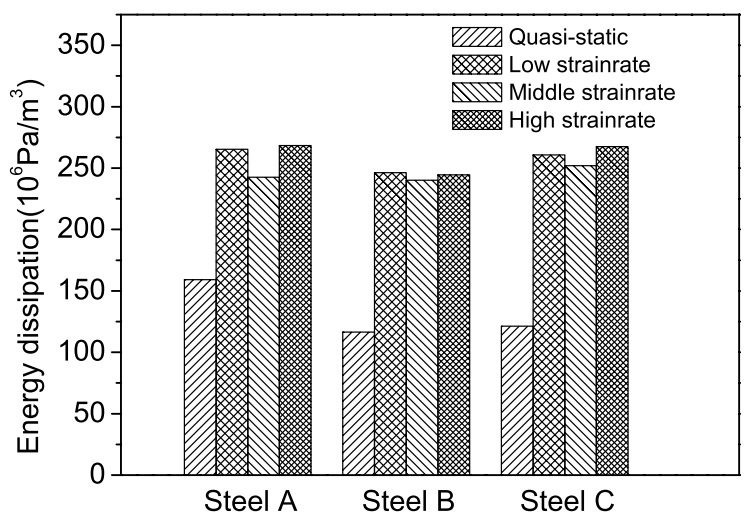

Fig. 13. Influence of the strain rate on the energy absorption.

Table 2. The Johnson-Cook Model Parameters for the investigated Steel Grades.

\begin{tabular}{|c|c|c|c|c|c|}
\hline & $A$ & $B$ & $n$ & $C$ & $m$ \\
\hline Steel A & 473 & 601 & 0.66 & 0.016 & 0.8 \\
\hline Steel B & 699 & 740 & 0.78 & 0.009 & 1.5 \\
\hline Steel C & 470 & 703 & 0.70 & 0.019 & 0.9 \\
\hline
\end{tabular}

static experiments. $A$ equals the yield stress of material in quasi-static experiments, and $B, n$ can be obtained from fitting the climbing part of the true stress vs. effective plastic strain curves.

Step 2: Parameter $C$ is derived from using the yield stress points of high-strain-rate experiments curves to fit the Eq. (5), at the yield stress points the effective plastic strain equals zero and the temperature increase is beginning.

Step 3: High-strain-rate true stress vs. effective plastic strain curves are adiabatic cures, and the temperature increase vs. effective plastic strain curves can be obtained, parameter $m$ can be derived from fitting the climbing part of the true stress vs. effective plastic strain curves of highstrain-rate.

In Table 2, the value of the Johnson-Cook model parameters calculated for the investigated steel grades is given. In Figs. 14-16, the curves obtained with the 


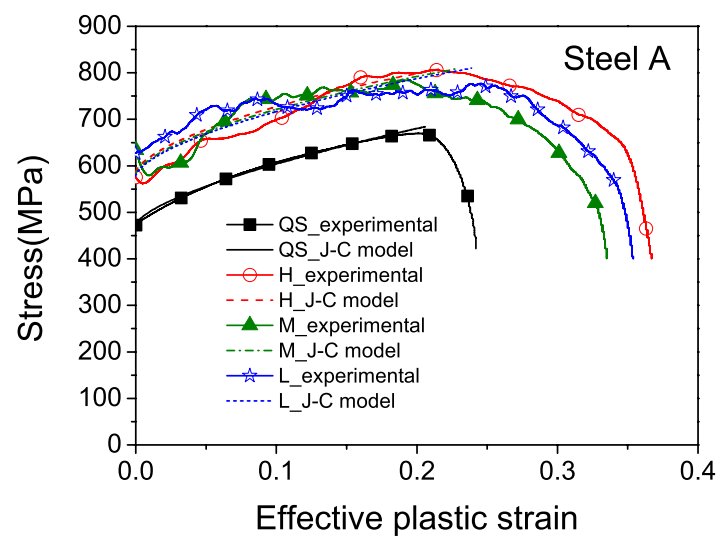

Fig. 14. Comparison of Johnson-Cook model predictions with experimental results for steel A.

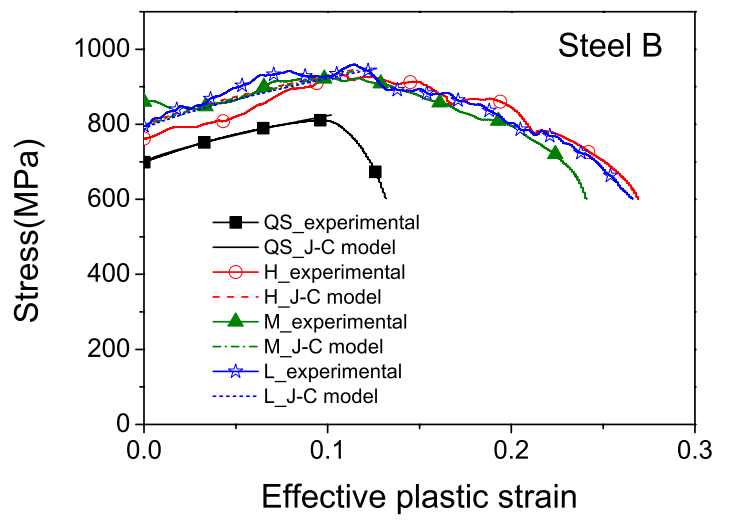

Fig. 15. Comparison of Johnson-Cook model predictions with experimental results for steel $\mathrm{B}$.

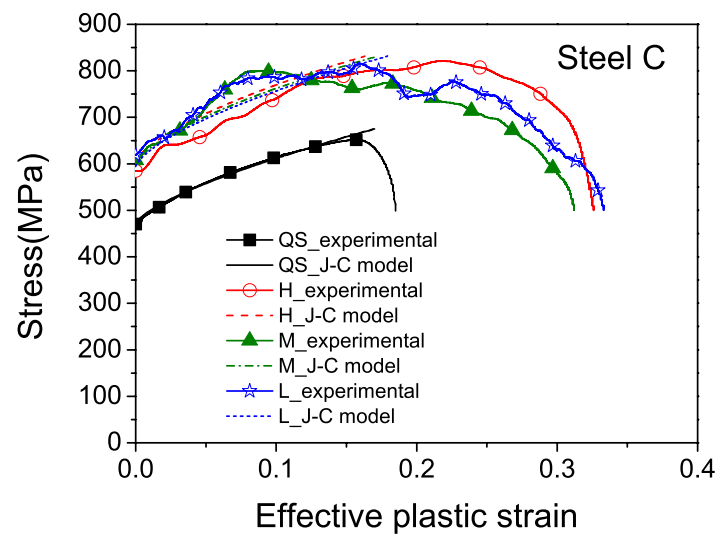

Fig. 16. Comparison of Johnson-Cook model predictions with experimental results for steel $\mathrm{C}$.

Johnson-Cook model are compared with an experimentally obtained stress-strain curve for the three investigated steel grades. It can be seen that the constitutive fit follows the experimental data very well.

\section{Conclusion}

Results are presented of an extensive study of the strainrate-dependent behavior of three steels. Split Hopkinson tensile bar tests are performed to obtain the stress-strain curves at higher strain rates. These materials combine higher strength with higher ductility and therefore offer more excellent crash energy absorption potential than quasi-static loading. In the range of dynamic strain rates considered in this paper, only minor differences exist between the dynamic curves are due to the mechanical behavior has a logarithmic dependence on strain rate for the three investigated steel grades. Compare to these three steels at dynamic strain rate, steel B performs highest strength value but lowest elongation level, so the energies absorbed of three steels are nearly equaled.

It is also shown that phenomenological models can describe the complex strain rate and temperature-dependent behavior. This allows numerical simulation of structures made of these steels. For all the three steels, the JohnsonCook model was found to result in a good fit with the experimental data.

\section{Acknowledgements}

The authors gratefully acknowledge the financial support of the Natural Science Foundation of China (NSFC) through Grant No. $11172328 \& 11132012$, and the foundation of National University of Defense Technology through Grant No. JC-11-02-17.

\section{References}

1. A. Wasilkowska, P. Tsipouridis, E. A. Werner, A. Pichler and S. Traint, J. Mater. Process. Tec, 633, 157-158, (2004).

2. W. Bleck, Proc. Int. Conf. on TRIP-Aided High Strength Ferrous Alloys, 13, (2002).

3. Alexander Bardelcik, Christopher P. Salisbury, Int. J. Imp. Eng, 37, 694-702, (2010).

4. J. Van Slycken, P. Verleysen, et al., Mater. Sci. Eng. A, 516-524, (2007).

5. X. Sun, et al., Mater. Sci. Eng. A (2012). (to be published).

6. E. Davies and S. Hunter, J. Mech. Phys. Solids, 11, 155 (1963).

7. H. Kolsky, Proc. Phys. Soc. Lond. Sec. B 62, 676, (1949).

8. G.R. Johnson and W.H. Cook, Proc. 7th Int. Symp. Ballistics, 541-547, 1983.

9. H. Zhao, Mater. Sci. Eng. A, 230, 95-99, (1997).

10. A. Mark, D. Boyd, and E. Essadiqi, Int. Conf. on Advanced High Strength Sheet Steels for Automotive Applications, 307-313, 2004. 